\title{
Nurses' Compliance with Infection Control Standard Precautions in Dialysis Units
}

\author{
Rania Elsayed Mohamed, Clinical Instructor \\ Nursing Administration, Faculty of Nursing, Damanhour University \\ Neamat Mohamed El-Sayed, Professor \\ Nursing Administration, Faculty of Nursing, Damanhour University \\ Heba Mohamed Alanwer Ashour, Lecturer \\ Nursing Administration, Faculty of Nursing, Alexandria University \\ * Corresponding author: Rania Elsayed Mohamed \\ E-mail: elrania691@ gmail.com
}

\begin{abstract}
Infection is the highest general cause of hospitalization and the second common cause of death between hemodialysis patients (HD).So, stricter measures such as infection control standard precautions are specifically recommended in hemodialysis units to avoid the spread of these infectious microorganisms. Objective: Assess nurses' compliance with infection control standard precautions. Settings: This study was conducted in Abo Homos Hospital (outpatients dialysis unit with 27 beds) and Kafr El Dwar General Hospital (out patients dialysis unit with 32 beds). Subjects: The sample included all staff nurses who were available at the time of data at selected setting. Tools: An Observational Checklist used for data collection included three parts; Part I: includes personal characteristics, Part II: includes items related to infection control standard precautions and Part III: includes items related to environmental design. Results: All staff nurses in Kafr El Dwar General Hospital had a moderate level of compliance to infection control standard precaution in evening shifts. While, $73.3 \%$ of them had a moderate level of compliance to infection control standard precautions at morning shifts. All staff nurses in Abo Homos Hospital had a moderate level of compliance to infection control standard precaution in morning shifts. While, only $93.5 \%$ of them had a moderate level of compliance to infection control standard precautions at evening shifts. Conclusion: This study reported that the total nurses' compliance level with infection control standard precaution were moderate at both hospitals. Recommendations: This study suggested an implementation of regular training programs and refreshing courses to nurses to improve their knowledge and provide sufficient facilities and equipment required to maintain good infection control practice in both morning and evening shifts equally.
\end{abstract}

Keywords: Nurses, Hemodialysis; Infection Control Standard Precautions; Compliance.

\section{Introduction}

Standard precautions are set of guidelines of infection control practices which characterize the most recent and complete guidelines for the inhibition of infectious risk (Neo et al., 2013). Also it wins as the first line of protection against exposure to bodily fluids such as secretions, mucous membranes, blood and non-contact skin (Haile et al., 2017). Indeed, these standards are mentioned by different international organizations such as; Centre of disease control (CDC), European Best Practice Guidelines (EPBG), United States of America, World Health Organization (WHO) and Association of Professionals in Infection Control (APIC) (HernándezGarcía\& Cardoso, 2013; Nasiri et al., 2019). Practicing of SPs entails: hand hygiene, use of suitable personal protective equipment (PPEs), safe handling of potentially polluted surfaces or equipment, environmental cleaning, linen management and waste management. As well as in 2007, CDC added safe injection practices and respiratory hygiene and/or cough etiquette 
(Centers for Desease Control and Prevention (CDC), 2001; Oh \& Choi, 2019).

Poor infection control, producing healthcare-associated infections. So, compliance with standard precautions (SPs) is the primary strategy for the avoidance of Hospital Acquired Infection (HAIs) (Benedetta-Allegranzi, 2011; Donati et al., 2019; Stilo et al., 2016). Compliance is defined as the degree to which advice behavior is adhered to. Poor compliance with infection control (IC) practices at HD unit happens as a result of one or more of the following causes: (a) lack or insufficient training and lower level of knowledge amongst HD staff, (b) understaffing with poor nurse to patient ratio, (c) inadequate provision of necessary supplies/equipment, (d) frequent turn-over of nursing staff, (e) poor design of HD unit (Jeanes et al., 2020; Russell et al., 2018). Internationally, a study was done in Saudi University by Colet et al. (2017) to assess compliance with standard precautions between baccalaureate nursing students. It was found that there were variations in compliance level with standard precautions, the highest compliance level were in the disposing of used of sharps and the lowest compliance level were in not recapping used syringes after injection.

In Egypt, a study was done by Ramadan (2016) and by Moursy and Sharaf (2017) they showed that the highest percentage of study nurses didn't comply with infection control standard precautions.

\section{Significance of the study:}

This study will provide valuable needed information for formulating evidence based training programs to improve area with slight compliance rate, increase knowledge about infection control measures, decrease infection rate at dialysis unit, improve quality of patient care, patient satisfaction and improve reputation of Abo Homes Hospital and Kafr El- Dwar General Hospital.

\section{Aims of the Study}

This study aimed to assess nurses' compliance with infection control standard precautions in dialysis department at Abo Homos Hospital and Kafr El-Dwar General Hospital.

\section{Research Question}

What is the nurses' compliance level to infection control standard precautions in dialysis department at Abo Homos Hospital and Kafr El-Dwar General Hospital?

\section{Materials and Method}

\section{Materials}

Design: A descriptive research design was used to conduct this study.

Settings: The present study was conducted at two hospitals affiliated to the Ministry of Health. Abo Homos Hospital with 151 beds (out patients dialysis unit with 27 beds) and Kafr El Dwar General Hospital with 278 beds (out patients dialysis unit with 32 beds).

Subjects: This study included: all staff nurses who were available at the time of data collection, in the previously mentioned setting $(n=61)$. At Abo Homos Hospital $(n=31)$ classified as professional nurse $(n=15)$ and technical nurse $(n=16)$ and all staff nurses who were available at the time of data collection at Kafr El-Dwar General Hospital $(n=30)$ classified as professional nurse $(n=16)$ and technical nurse $(n=14)$.

Tool: One tool was used for the purpose of this study:

Tool I: Hemodialysis Nurses Compliance with Infection Control Standard Precautions and Environmental Design Observation Checklist

An observation checklist adopted from Akl (2014) and Noaman (2016) to assess nurses' compliance to infection control standard precautions and environmental design, which consisted of three parts: 
The first part was related to nurses' personal characteristics; such as such as years of experience, educational qualification, date of employment, shift, age, sex and marital status.

The second part consisted of 85 items, to assess nurses' compliance with infection control standard precautions which is divided into 9 groups as follows; Hand hygiene ( $\mathrm{n}=13$ items ), personal protective equipment $(\mathrm{n}=6$ items), clinical practice $(\mathrm{n}=32$ items), specimen handling $(\mathrm{n}=6$ items), safe handling and disposal of sharps $(\mathrm{n}=5$ items), spillage and contamination with body/blood fluid ( $n=4$ items), vaccine transporting and storage ( $\mathrm{n}=2$ items), waste disposal ( $\mathrm{n}=10$ items), safe handling of linen $(\mathrm{n}=7$ items).

Observations was measured on 3 point scales; a score of 3 was given for completely done, 2 for partial done, 1 for not done and 0 for items that not applied for certain nurses.

- Low level $=0-83$ score

- $\quad$ Moderate level $=84-125$ score

- High level= 126 - 168 score

The third part consisted of 17 items related to environmental design, to assess hemodialysis unit physical set up, which is divided into 3 dimensions as follows; physical set up structure area ( $\mathrm{n}=8$ items), equipment and supply storage $(\mathrm{n}=3$ items) and presence of policies ( $n=6$ items).

Observations was measured on 2 point scales; a score of 2 was given for available and adequate, 1 for available and inadequate and 0 for not available.

- Low level $=0$ - 16 score

- $\quad$ Moderate level = 17-24 score

- High level = 25- 34 score

\section{Method}

\section{The study design accomplished as follows:}

- An official letter from the Faculty of nursing- Damanhour University was sent to the Hospital Administrator seeking his approval for conducting the study, After his approval, the formal letter was sent to Director of Hemodialysis unit as well as first line Nurse Manager in the unit and a written approval was obtained from them after explaining the aim of the study.

- Tool was tested for content validity by a jury of five experts in the field of study (two assistant Professors of Nursing Administrators, Damanhour University, one Professor of Nursing Administration, Alexandria University and two Professors of Nursing Administration, Tanta University). Accordingly, simple modifications were made such as clarification of some words.

- A pilot study was carried out for $10 \%$ $(n=6)$ of the participants rather than the study to ensure and check clarity and applicability of tool, identify obstacles and problems that may be encountered during data collection, no modifications were made.

- Data collection was conducted for study sample by the researcher using observational checklist to monitor nurses' compliance with infection control standard precautions in dialysis department through intermitted observation. Each nurse was observed for two times at different two shifts. Once at morning and once at evening shift, each nurse took about 3 hours for observation as it is the most time they provide the direct patient care. Data collection took a period of two months started from 15/5/2020 till 15/7/2020.

\section{Ethical considerations:}

- A research plan was submitted to the Ethics Committee, Faculty of Nursing, Damanhour University for research approval.

- A written informed consent was obtained from identified nurses to 
collect data of study after explanation the aim of study.

- Confidentiality of the data, anonymity and privacy of the study subject was maintained

- Freedom to withdraw from the study was assured.

\section{Statistical Analysis}

- The collected data was revised, categorized, coded, computerized, tabulated and entered in special format to be suitable for computer feeding.

- Following data entry, checking and verification process were carried out in order to avoid any errors.

- Data were analyzed using the statistical package for social science SPSS (version 25).

\section{Results}

Table (1) reflects staff nurses' compliance level to infection control standard precautions at Kafr El Dwar General Hospital by shift. As can be seen, majority of nurses $(86.65 \%)$ had moderate level at both shifts. All staff nurses had a moderate level of compliance to infection control standard precaution in evening shifts. While, $73.3 \%$ of them had a moderate level of compliance to infection control standard precautions at morning shifts and $26.7 \%$ of them had high level. The highest percentage of nurses had low compliance with infection control standard precaution regarding, personal protective equipment while, linen management and management of spillage had the higher percentage of nurses' compliance.

Table (2) reflects level of staff nurses' compliance to infection control standard precautions at Abo Homos Hospital by shift. As can be seen, majority of nurses $(96.75 \%)$ had moderate level at both shifts. All staff nurses had a moderate level of compliance to infection control standard precaution in morning shifts. While, only $93.5 \%$ of them had a moderate level of compliance to infection control standard precautions at evening shifts and no one of them had a high level at both shifts. The highest percentage of nurses had low compliance with infection control standard precaution regarding, personal protective equipment and hand hygiene while, waste disposal and linen management had the higher percentage of nurses' compliance.

\section{Discussion}

The result of this study revealed that the total nurses' compliance with infection control standard precautions was moderate level at both Kafr El- Dwar General and Abo Homos Hospitals. This finding may be related to insufficient supply of resources such as, inadequate supplies and equipment, negligence attitude, lack of supervision, inadequate training and insufficient support from management to facilitating work. This result is supported by Jawaid et al. (2009) and Porto and Marziale (2016) who revealed that insufficient knowledge, workload and inadequate supplies, equipment and training is the major causes of noncompliance with SPs. However this result inconsistent with Labrague et al. (2012) and Nofal et al. (2017) who revealed higher compliance rate with SPs among staff nurses in their studies.

Also, this study reported that the total mean score of nurses' compliance with infection control standard precautions was high at morning than evening shifts at both hospitals. This may be attributed to that morning shifts characterized by presence of head nurse, adequate supplies and equipment, and adequate number of nurses in the morning shifts whom responsible for patients in the unit. Moreover in the evening shifts, there were inadequate supplies and equipment, supervision and monitoring by the senior staff and the infection control committee members. This result is supported by Noaman (2016) Moursy and Sharaf (2017) who revealed that nurses' compliance with SPs at the morning shifts had higher score than those at the evening shifts due to 
the lack of time, nurses' staff shortage, lack of supervision and the workload in HD unit. This result was contradicted by Sharir et al. (2001) who concluded that more hand washing compliance was observed during the evening shift compared with the morning shift.

\section{Dimensions of infection control standard precautions:}

Regarding hand hygiene: The present study demonstrates that the highest percentage of nurses had low compliance level with infection control standard precaution were regarding, hand hygiene (33.3\%-58.05) at both hospitals. this result may be related to availability of hand washing sinks but washing supplies not adequate, nurses incompletely use the correct six steps of hand wash techniques but nurses did not washing hands after removal of gloves, lack of policy that determine fixed punishment for noncompliance with fixed procedures by all nurses. Lack of motivation and over work load. This result agreed with Scheithauer et al. (2017) who concluded that the higher the workload, the lower compliance and a lack of motivation may be the major two causes of poor compliance. Also, this result agreed with Niyonzima et al. (2018) who reported that insufficient number or inaccessible sinks as well as inconveniently placed sinks and inadequate number of $\mathrm{HH}$ resources were considerably a highly ranked cause for non-compliance with hand hygiene. In contrast, the study was done at Ghana by Ashinyo et al. (2021) who demonstrated that high compliance levels (88.4\%) for hand hygiene.

Personal protective equipment: The current study revealed that the highest percentage of nurses had low compliance with infection control standard precaution were regarding, personal protective equipment $(66.15 \%-66.6 \%)$ at both hospitals respectively. This may be attributed to negligence to attitude, unavailability of supplies almost all of the time, lack of up- to date training on the principles of standard precautions, almost all nurses not used gloves as a single use or changed between two patients or to the same patient. This result in accordance with Sa et al. (2016) who revealed that the most commonly reason for noncompliance was non availability of personal protective devices and health care providers being too busy to use PPE and lack of awareness of health care providers about the importance of adherence to usage of PPE.

On the other hand this result disagreed with the study was conducted at Jordan University by Eskander et al. (2013).

In relation to safe handling and disposal of sharps, this study showed that safe handling and disposal of sharps had the higher percentage of nurses' had high compliance level (65\%).

Concerning safe handling and disposal of sharps, had the higher percentage of nurses' had high compliance level (65\%$51.6 \%$ ) respectively at both hospitals. This finding may be related to these compliant nurses didn't recap or bend the used needles. They were also disposing of the used needles at the safety box. All sharps bins were labeled with points of source and signed and nurses not decanted sharps from one receptacle to another and nurses' awareness of the danger of needle-stick injuries from the infection control committee and implementation of sharps disposal policy. This result is consistent with Ella et al. (2016) who revealed that sufficient supply of injection safety material, availability of injection safety guidelines and adequate training is the major cause of nurses' compliance. By contrast, Elagamy (2014) and Haridi et al. (2016) who reported low nurses' compliance with sharps handling.

Concerning waste disposal, had the higher percentage of nurses' had high compliance level $(51.65 \%)$ at Abo Homos Hospitals. This may be due to the availability of color bags, restrict punishment for those who don't comply with 
waste management, continuous surveillance of segregation practices by hospital infection control committee and encouraging prompt reporting and implement of infection control guidelines at morning shifts.

This finding was supported by Gebresilassie et al. (2014) and Hakim et al. (2014) they reported high level of compliances with waste disposal among nurses. On the other hand, this study was contradicted by Tabash and Ashraf (2018) and Njue et al. (2015) who concluded that nurses' compliance of waste disposal level was low.

\section{Conclusion}

Based on the findings of this study it could be concluded that:

- The nurses' compliance levels with infection control standard precautions were moderate at both hospitals.

- Kafr El- Dwar General Hospital had higher mean score of compliance with infection control standard precautions than those at Abo Homos Hospital at both shifts.

\section{Recommendations}

This study recommended that:

\section{A. Directors of hospital should:}

- Provide in service education programs for all nurses to keep them up data regarding infection control measures

- Conduct frequent periodic meeting and discussion with infection control team and hemodialysis supervisor to identify their needs.

- Establish follow up system at dialysis unit to ensure application of all infection control procedures.

\section{B. Infection control team should:}

- Provide written policies and infection control procedures at $\mathrm{HD}$ units and review it.

- Assess and follow up nurses' compliance with infection control standard precautions at HD units 
Table (1): Levels of staff nurses' compliance to infection control standard precautions at Kafr El Dwar General Hospital by shift

\begin{tabular}{|c|c|c|c|c|c|}
\hline \multirow{3}{*}{ Items } & \multicolumn{4}{|c|}{ 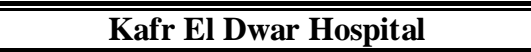 } & \multirow{3}{*}{$\begin{array}{c}\text { Total } \\
\%\end{array}$} \\
\hline & \multicolumn{2}{|c|}{ Morning $(n=30)$} & \multicolumn{2}{|c|}{ Evening $(n=30)$} & \\
\hline & No & $\%$ & No & $\%$ & \\
\hline \multicolumn{6}{|c|}{ 1. Hand hygiene } \\
\hline Low & 6 & 20.0 & 14 & 46.7 & 33.35 \\
\hline Moderate & 19 & 63.3 & 16 & 53.3 & 58.3 \\
\hline High & 5 & 16.7 & 0 & 0.0 & 8.35 \\
\hline \multicolumn{6}{|c|}{ 2. Personal Protective Equipment } \\
\hline Low & 15 & 50.0 & 25 & 83.3 & 66.6 \\
\hline - $\quad$ Moderate & 10 & 33.3 & 5 & 16.7 & 25 \\
\hline - High & 5 & 16.7 & 0 & 0.0 & 8.35 \\
\hline \multicolumn{6}{|c|}{ 3. Clinical Practices } \\
\hline - Low & 1 & 3.3 & 0 & 0.0 & 1.65 \\
\hline - $\quad$ Moderate & 29 & 96.7 & 30 & 100.0 & 98.35 \\
\hline - $\quad$ High & 0 & 0.0 & 0 & 0.0 & 0.0 \\
\hline \multicolumn{6}{|c|}{ 3.a Central Venous Catheter } \\
\hline - $\quad$ Low & 6 & 20.0 & 10 & 33.3 & 26.65 \\
\hline - $\quad$ Moderate & 19 & 63.3 & 14 & 46.7 & 55.0 \\
\hline - $\quad$ High & 5 & 16.7 & 6 & 20.0 & 18.35 \\
\hline \multicolumn{6}{|c|}{ 3.b Intravenous injection } \\
\hline - $\quad$ Low & 2 & 6.7 & 1 & 3.3 & 5.0 \\
\hline - $\quad$ Moderate & 28 & 93.3 & 29 & 96.7 & 95 \\
\hline - High & 0 & 0.0 & 0 & 0.0 & 0.0 \\
\hline \multicolumn{6}{|c|}{ 3.c Intramuscular injection } \\
\hline - Low & 7 & 23.3 & 7 & 23.3 & 23.3 \\
\hline - Moderate & 13 & 43.3 & 14 & 46.7 & 45 \\
\hline - High & 10 & 33.3 & 5 & 30.0 & 31.65 \\
\hline \multicolumn{6}{|c|}{ 3.d Canula insertion } \\
\hline Low & 6 & 20.0 & 5 & 16.7 & 18.35 \\
\hline - $\quad$ Moderate & 14 & 46.7 & 22 & 73.3 & 60 \\
\hline - High & 10 & 33.3 & 3 & 10.0 & 21.65 \\
\hline \multicolumn{6}{|c|}{ 4. Specimen handling } \\
\hline - Low & 9 & 30.0 & 9 & 30.0 & 30.0 \\
\hline - Moderate & 18 & 60.0 & 18 & 60.0 & 60.0 \\
\hline - High & 3 & 10.0 & 3 & 10.0 & 10.0 \\
\hline \multicolumn{6}{|c|}{ 5. Safe handling and disposal of sharps } \\
\hline - Low & 0 & 0.0 & 0 & 0.0 & 0.0 \\
\hline - $\quad$ Moderate & 9 & 30.0 & 12 & 40.0 & 35.1 \\
\hline - $\quad$ High & 21 & 70.0 & 18 & 60.0 & 65 \\
\hline \multicolumn{6}{|c|}{ Management of spillage } \\
\hline - Low & 1 & 3.3 & 0 & 0.0 & 1.65 \\
\hline - $\quad$ Moderate & 11 & 36.7 & 12 & 40.0 & 38.35 \\
\hline - High & 18 & 60.0 & 18 & 60.0 & 60.0 \\
\hline \multicolumn{6}{|c|}{ 6. Management of vaccination } \\
\hline Low & 0 & 0.0 & 2 & 6.7 & 3.35 \\
\hline - Moderate & 19 & 63.3 & 18 & 60.0 & 61.65 \\
\hline - $\quad$ High & 11 & 36.7 & 10 & 33.3 & 35 \\
\hline \multicolumn{6}{|c|}{ 7. Waste disposal } \\
\hline Low & 0 & 0.0 & 0 & 0.0 & 0.0 \\
\hline - $\quad$ Moderate & 12 & 40.0 & 20 & 66.7 & 53.35 \\
\hline - $\quad$ High & 18 & 60.0 & 10 & 33.3 & 46.65 \\
\hline 8. $\quad$ Linen & & & & & \\
\hline - $\quad$ Low & 0 & 0.0 & 0 & 0.0 & 0.0 \\
\hline - $\quad$ Moderate & 11 & 36.7 & 13 & 43.3 & 40 \\
\hline - High & 19 & 63.3 & 17 & 56.7 & 60 \\
\hline Total nurses' & on c & stand & preca & & \\
\hline - $\quad$ Low & 0 & 0.0 & 0 & 0.0 & 0.0 \\
\hline - $\quad$ Moderate & 22 & 73.3 & 30 & 100.0 & 86.65 \\
\hline - $\quad$ High & 8 & 26.7 & 0 & 0.0 & 13.35 \\
\hline
\end{tabular}


Table (2): Level of staff nurses' compliance to infection control standard precautions at Abo Homos Hospital by shift

\begin{tabular}{|c|c|c|c|c|c|}
\hline \multirow{3}{*}{ Items } & \multicolumn{4}{|c|}{ Abo Homos Hospital } & \multirow{3}{*}{$\begin{array}{c}\text { Total } \\
\%\end{array}$} \\
\hline & \multicolumn{2}{|c|}{ Morning $(n=31)$} & \multicolumn{2}{|c|}{ Evening $(n=31)$} & \\
\hline & No & $\%$ & No & $\%$ & \\
\hline \multicolumn{6}{|c|}{ 1. Hand hygiene } \\
\hline - Low & 8 & 25.8 & 28 & 90.3 & 58.05 \\
\hline - $\quad$ Moderate & 23 & 74.2 & 3 & 9.7 & 41.95 \\
\hline - High & 0 & 0.0 & 0 & 0.0 & 0.0 \\
\hline \multicolumn{6}{|c|}{ 2. Personal Protective Equipment } \\
\hline - Low & 19 & 61.3 & 22 & 71.0 & 66.15 \\
\hline - $\quad$ Moderate & 9 & 29.0 & 8 & 25.8 & 41.9 \\
\hline - High & 3 & 9.7 & 1 & 3.2 & 6.45 \\
\hline \multicolumn{6}{|c|}{ 3. Clinical Practices } \\
\hline - $\quad$ Low & 0 & 0.0 & 4 & 12.9 & 6.45 \\
\hline - $\quad$ Moderate & 31 & 100.0 & 27 & 87.1 & 93.55 \\
\hline - High & 0 & 0.0 & 0 & 0.0 & 0.0 \\
\hline \multicolumn{6}{|c|}{ 3.a Central Venous Catheter } \\
\hline - Low & 10 & 32.3 & 8 & 25.8 & 29.05 \\
\hline - $\quad$ Moderate & 16 & 51.6 & 18 & 58.1 & 54.85 \\
\hline - High & 5 & 16.1 & 5 & 16.1 & 16.1 \\
\hline \multicolumn{6}{|c|}{ 3.b Intravenous injection } \\
\hline - $\quad$ Low & 1 & 3.2 & 2 & 6.5 & 4.85 \\
\hline - $\quad$ Moderate & 30 & 96.8 & 29 & 93.5 & 95.15 \\
\hline - $\quad$ High & 0 & 0.0 & 0 & 0.0 & 0.0 \\
\hline \multicolumn{6}{|c|}{ 3.c Intramuscular injection } \\
\hline - Low & 2 & 6.5 & 7 & 22.6 & 14.55 \\
\hline - $\quad$ Moderate & 21 & 67.7 & 18 & 58.1 & 62.9 \\
\hline - High & 8 & 25.8 & 6 & 19.4 & 22.6 \\
\hline \multicolumn{6}{|c|}{ 3.d Canula insertion } \\
\hline - Low & 4 & 12.9 & 9 & 29.0 & 20.95 \\
\hline - $\quad$ Moderate & 23 & 74.2 & 21 & 67.7 & 70.95 \\
\hline - High & 4 & 12.9 & 1 & 3.2 & 8.05 \\
\hline \multicolumn{6}{|c|}{ 4. Specimen handling } \\
\hline - Low & 5 & 16.1 & 4 & 12.9 & 14.5 \\
\hline - $\quad$ Moderate & 20 & 64.5 & 24 & 77.4 & 70.95 \\
\hline - High & 6 & 19.4 & 3 & 9.7 & 14.55 \\
\hline \multicolumn{6}{|c|}{ 5. Safe handling and disposal of sharps } \\
\hline - $\quad$ Low & 0 & 0.0 & 0 & 0.0 & 0.0 \\
\hline - $\quad$ Moderate & 16 & 51.6 & 14 & 45.2 & 84.4 \\
\hline - High & 15 & 48.4 & 17 & 54.8 & 51.6 \\
\hline \multicolumn{6}{|c|}{ 6. Management of spillage } \\
\hline - $\quad$ Low & 1 & 3.2 & 1 & 3.2 & 3.2 \\
\hline - $\quad$ Moderate & 16 & 51.6 & 21 & 67.7 & 59.6 \\
\hline - High & 14 & 45.2 & 9 & 29.0 & 37.1 \\
\hline \multicolumn{6}{|c|}{ 7. Management of vaccination } \\
\hline - $\quad$ Low & 0 & 0.0 & 3 & 9.7 & 4.85 \\
\hline - $\quad$ Moderate & 26 & 83.9 & 22 & 71.0 & 77.45 \\
\hline - High & 5 & 16.1 & 6 & 19.4 & 17.75 \\
\hline \multicolumn{6}{|c|}{\begin{tabular}{|l|} 
8. Waste disposal \\
\end{tabular}} \\
\hline - Low & 0 & 0.0 & 0 & 3.2 & 1.6 \\
\hline - $\quad$ Moderate & 13 & 41.9 & 16 & 51.6 & 46.75 \\
\hline - High & 18 & 58.1 & 14 & 45.2 & 51.65 \\
\hline 9. Linen & & & & & \\
\hline - Low & 0 & 0.0 & 0 & 0.0 & 0.0 \\
\hline - $\quad$ Moderate & 12 & 38.7 & 26 & 80.6 & 59.65 \\
\hline - High & 19 & 61.3 & 6 & 19.4 & 40.35 \\
\hline Total nurses' & ion $\mathrm{c}$ & stand & preca & & \\
\hline - Low & 0 & 0.0 & 2 & 6.5 & 3.25 \\
\hline - $\quad$ Moderate & 31 & 100.0 & 29 & 93.5 & 96.75 \\
\hline - High & 0 & 0.0 & 0 & 0.0 & 0.0 \\
\hline
\end{tabular}




\section{References}

- Akl, H. F. A. (2014). The Relationship Between Using Infection Control Standards Internal Audit and Performance (Unpublished Master Thesis) [Master Thesis]. Alaxandria University, Faculty of Nuesing.

- Ashinyo, M. E., Dubik, S. D., Duti, V., Amegah, K. E., Ashinyo, A., Asare, B. A., Ackon, A. A., Akoriyea, S. K., \& KumaAboagye, P. (2021). Infection prevention and control compliance among exposed healthcare workers in COVID-19 treatment centers in Ghana: A descriptive crosssectional study. PloS one, 16(3), e0248282e0248282.

https://doi.org/10.1371/journal.pone.02482

$\underline{82}$.

- Benedetta-Allegranzi, S. (2011). Report on the Burden of Endemic Health CareAssociated Infection Worldwide Clean Care is Safer Care. World Health Organization (WHO).

- Centers for Desease Control and Prevention (CDC). (2001). Inside: Continuing Education Examination es Nurses Inside: Medical Education for Recommendations for Preventing Transmission of Infections Among. CDC.

- Colet, P. C., Cruz, J. P., Alotaibi, K. A., Colet, M. K. A., \& Islam, S. M. S. (2017). Compliance with standard precautions among baccalaureate nursing students in a Saudi university: A self-report study. Journal of infection and public health, 10(4), 421-430. https://doi.org/10.1016/j.jiph.2016.06.005.

- Donati, D., Biagioli, V., Cianfrocca, C., De Marinis, M. G., \& Tartaglini, D. (2019). Compliance with Standard Precautions among Clinical Nurses: Validity and Reliability of the Italian Version of the Compliance with Standard Precautions Scale (CSPS-It). International journal of environmental research and public health, 16(1), 121. https://doi.org/10.3390/ijerph16010121.

- Elagamy, E. M. (2014). Nurses' Compliance with Infection control Guidelines At Governmental Maternity
Hospital In Alexandria [Master Thesis]. Alexandria Universty, Faculty of Nursing.

- Ella, R. E., Osuchukwu, E. C., AkpanIdiok, P. A., \& Kanu, S. E. (2016). Knowledge and practice of injection safety among Nurses at University of Calabar Teaching Hospital (UCTH), Calabar, Nigeria: Implications for nursing education. Global Journal of Pure and Applied Sciences, 22(1), 81-90.

- Eskander, H. G., Morsy, W. Y. M., \& Elfeky, H. A. A. (2013). Intensive care nurses' knowledge \& practices regarding infection control standard precautions at a selected Egyptian cancer hospital. Prevention, 4(19), 160-174.

- Gebresilassie, A., Kumei, A., \& Yemane, D. (2014). Standard Precautions Practice among Health Care Workers in Public Health Facilities of Mekelle Special Zone, Northern Ethiopia. Journal of Community Medicine and Health Education, 4(1), 286$290 . \quad$ https://doi.org/10.4172/2161$\underline{0711.1000286}$.

- Haile, T. G., Engeda, E. H., \& Abdo, A. A. (2017). Compliance with Standard Precautions and Associated Factors among Healthcare Workers in Gondar University Comprehensive Specialized Hospital, Northwest Ethiopia. Journal of environmental and public health, 2017, 2050635-2050635. https://doi.org/10.1155/2017/2050635.

- Hakim, S. A., Mohsen, A., \& Bakr, I. (2014). Knowledge, attitudes and practices of health-care personnel towards waste disposal management at Ain Shams University Hospitals, Cairo. Eastern Mediterranean Health Journal, 20(5), 347354.

- Haridi, H. K., Al-Ammar, A. S., \& AlMansour, M. I. (2016). Compliance with infection control standard precautions guidelines: a survey among dental healthcare workers in Hail Region, Saudi Arabia. Journal of infection prevention, 17(6), 268-276. https://doi.org/10.1177/175717741664534. 
- Hernández-García, I., \& Cardoso, A. (2013). Hand hygiene compliance and determining factors among Spanish nursing students. American journal of infection control, 41(10), 943-944. https://doi.org/10.1016/j.ajic.2013.01.012.

- Jawaid, M., Iqbal, M., \& Shahbaz, S. (2009). Compliance with Standard Precautions: A long way ahead. Iranian J Public Health, 38(1), 85-88. Retrieved from https://ijph.tums.ac.ir/index.php/ijph/article /view/3215.

- Jeanes, A., Coen, P. G., Drey, N. S., \& Gould, D. J. (2020). Moving beyond hand hygiene monitoring as a marker of infection prevention performance: Development of a tailored infection control continuous quality improvement tool. American journal of infection control, 48(1), 68-76. https://doi.org/10.1016/j.ajic.2019.06.014.

- Labrague, L. J., Rosales, R. A., \& Tizon, M. M. (2012). Knowledge and Compliance of Standard Precautions among Student Nurses. Int J Adv Nurs Studies, 1(2), 8497.

- Moursy, A., \& Sharaf, A. (2017). Vascular access care at hemodialysis unit; nurses compliance to infection prevention and control practices. IOSR Journal of Nursing and Health Science (IOSR-JNHS), 6(2), 610.

- Nasiri, A., Balouchi, A., Rezaie-Keikhaie, K., Bouya, S., Sheyback, M., \& Rawajfah, O. A. (2019). Knowledge, attitude, practice, and clinical recommendation toward infection control and prevention standards among nurses: A systematic review. American journal of infection control, $\quad 47(7), \quad$ 827-833. https://doi.org/10.1016/j.ajic.2018.11.022.

- Neo, F., Edward, K.-L., \& Mills, C. (2013). Understanding compliance with protective eyewear amongst peri-operative nurses: A phenomenological inquiry. Australian Journal of Advanced Nursing, 31(1), 20-27.

- Niyonzima, V., Brennaman, L., \& Beinempaka, F. (2018). Practice and compliance of essential handwashing among healthcare workers at a regional referral hospital in Uganda: A quality improvement and evidence-based practice. Canadian Journal of Infection Control 33(1), 33-38.

- Njue, P. M., Cheboi, K. S., \& Shadrak, O. (2015). Adherence to Healthcare Waste Management Guidelines among Nurses and Waste Handlers in Thika Sub-countyKenya. Ethiopian journal of health sciences, 25(4), 295-304. https://doi.org/10.4314/ejhs.v25i4.

- Noaman, F. N. (2016). Infection control precautions of nosocomial infection at hemodialysis units [Master Thesis]. Alaxandria University, Faculty of Nuesing.

- Nofal, M., Subih, M., \& Al-Kalaldeh, M. (2017). Factors influencing compliance to the infection control precautions among nurses and physicians in Jordan: A crosssectional study. Journal of infection prevention, 18(4), 182-188. https://doi.org/10.1177/175717741769367.

- Oh, E., \& Choi, J. S. (2019). Factors influencing the adherence of nurses to standard precautions in South Korea hospital settings. American journal of infection control, 47(11), 1346-1351. https://doi.org/10.1016/j.ajic.2019.05.015.

- Porto, J. S., \& Marziale, M. H. (2016). Reasons and consequences of low adherence to standard precautions by the nursing team. Revista gaucha de enfermagem, 37(2), e57395. https://doi.org/10.1590/19831447.2016.02.57395.

- Ramadan, S. (2016). Nurses's Compliance With Standard Precautions in Intensive Care Units [UnPublished Master Thesis]. Faculty of Nursing, Alexandria University, Egypt.

- Russell, D., Dowding, D. W., McDonald, M. V., Adams, V., Rosati, R. J., Larson, E. L., \& Shang, J. (2018). Factors for compliance with infection control practices in home healthcare: findings from a survey of nurses' knowledge and attitudes toward infection control. American journal of infection control, 46(11), 1211-1217. https://doi.org/10.1016/j.ajic.2018.05.005. 
- Sa, H., Nf, A., \& Em, E. O. (2016). Use of personal protective devices among health care workers in a teaching hospital in Cairo, Egypt. Egyptian Journal of Occupational Medicine, 40(2), 287-300. https://doi.org/10.21608/ejom.2016.846.

- Scheithauer, S., Batzer, B., Dangel, M., Passweg, J., \& Widmer, A. (2017). Workload even affects hand hygiene in a highly trained and well-staffed setting: a prospective 365/7/24 observational study. Journal of Hospital Infection, 97(1), 11-16.

- Sharir, R., Teitler, N., Lavi, I., \& Raz, R. (2001). High-level handwashing compliance in a community teaching hospital: a challenge that can be met! The Journal of hospital infection, 49(1), 55-58. https://doi.org/10.1053/jhin.2001.1049.
- Stilo, A., Troiano, G., Melcarne, L., Gioffrè, M. E., Nante, N., Messina, G., \& Laganà, P. (2016). Hand washing in operating room: a procedural comparison. Epidemiol Biostatist Public Health, 13(3), e11732.

- Tabash, M., \& Ashraf, E. (2018). Compliance of healthcare staff towards infection control precautions in hemodialysis units - Gaza Governorates. Innovare Journal of Health Sciences, 6(1), 34-40. 